\title{
A Survey on Prediction Techniques of Heart Disease using Machine Learning
}

\author{
Mangesh Limbitote \\ Pimpri Chinchwad College of Engineering, \\ Nigdi, Pune - 411044, India \\ Kedar Damkondwar \\ Pimpri Chinchwad College of Engineering, \\ Nigdi, Pune - 411044, India
}

\author{
Dnyaneshwari Mahajan \\ Pimpri Chinchwad College of Engineering, \\ Nigdi, Pune - 411044, India \\ Pushkar Patil \\ Pimpri Chinchwad College of Engineering, \\ Nigdi, Pune - 411044, India
}

\begin{abstract}
Heart is one of the most important part of the body. It helps to purify and circulate blood to all parts of the body. Most number of deaths in the world are due to Heart Diseases. Some symptoms like chest pain, faster heartbeat, discomfort in breathing are recorded. This data is analysed on regular basis. In this review, an overview of the heart disease and its current procedures is firstly introduced. Furthermore, an in-depth analysis of the most relevant machine learning techniques available on the literature for heart disease prediction is briefly elaborated. The discussed machine learning algorithms are Decision Tree, SVM, ANN, Naive Bayes, Random Forest, KNN. The algorithms are compared on the basis of features. We are working on the algorithm with best accuracy. This will help the doctors to assist the heart problem easily.
\end{abstract}

Keywords-Machine Learning, Prediction, Classification Technique, Decision Tree, Accuracy.

\section{INTRODUCTION}

Heart disease is the kind of disease which can cause the death. Each year too many peoples are dying due to heart disease. Heart disease can be occurred due to the weakening of heart muscle. Also, the heart failure can be described as the failure of heart to pump the blood. Heart disease is also called as coronary artery disease (CAD). CAD can be occurred due to insufficient blood supply to arteries.

Heart disease can be detected using the symptoms like: high blood pressure, chest pain, hypertension, cardiac arrest, etc. There are many types of heart diseases with different types of symptoms. Like: 1) heart disease in blood vessels: chest pain, shortness of breath, pain in neck throat., 2)heart disease caused by abnormal heartbeats :slow heartbeat, discomfort, chest pain., etc. Most common symptoms are chest pain, shortness of breath, discomfort, chest pain., etc. Most common symptoms are chest pain, shortness of breath, fainting. Causes of heart disease are defects you're born with, high blood pressure, diabetes, smoking, drugs, alcohol. Sometimes in heart disease the infection also which affects the inner membrane which is identified by symptoms like fever, fatigue, dry cough, skin rashes. Causes of heart infection are bacteria, viruses, parasites. Types of heart disease: Cardiac arrest, Hypertension, Coronary artery disease, Heart failure, Heart infection, Congenital heart disease, Slow heartbeat, Stroke type heart disease, angina pectoris. Now a days there are too many automated techniques to detect the heart disease like data mining, machine learning, deep learning, etc. So, in this paper we will brief introduction about machine learning techniques. In this we train the datasets using the machine learning repositories. There are some risk factors on the basis of that the heart disease is predicted. Risk factors are: Age, Sex, Blood pressure, Cholesterol level, Family history of coronary illness, Diabetes, Smoking, Alcohol, Being overweight, Heart rate, Chest Pain.

\section{LITERATURE REVIEW}

There is number of works has been done related to disease prediction systems using different machine learning algorithms in medical Centre's.

Senthil Kumar Mohan et al,[1] proposed Effective Heart Disease Prediction Using Hybrid Machine Learning Techniques in which strategy that objective is to finding critical includes by applying Machine Learning bringing about improving the exactness in the expectation of cardiovascular malady. The expectation model is created with various blends of highlights and a few known arrangement strategies. We produce an improved exhibition level with a precision level of $88.7 \%$ through the prediction model for heart disease with hybrid random forest with a linear model (HRFLM) they likewise educated about Diverse data mining approaches and expectation techniques, Such as, KNN, LR, SVM, NN, and Vote have been fairly famous of late to distinguish and predict heart disease.

Sonam Nikhar et al [2] has built up the paper titled as Prediction of Heart Disease Using Machine Learning Algorithms by This exploration plans to give a point by point portrayal of Naïve Bayes and decision tree classifier that are applied in our examination especially in the prediction of Heart Disease. Some analysis has been led to think about the execution of prescient data mining strategy on the equivalent dataset, and the result uncovers that Decision Tree beats over Bayesian classification system.

Aditi Gavhane, Gouthami Kokkula, Isha Pandya, Prof. Kailas Devadkar (PhD), [3] Prediction of Heart Disease Using Machine Learning", In this paper proposed system they used the neural network algorithm multi-layer 
perceptron (MLP) to train and test the dataset. In this algorithm there will be multiple layers like one for input, second for output and one or more layers are hidden layers between these two input and output layers. Each node in input layer is connected to output nodes through these hidden layers. This connection is assigned with some weights. There is another identity input called bias which is with weight $b$, which added to node to balance the perceptron. The connection between the nodes can be feedforwarded or feedback based on the requirement.

Abhay Kishore et al,[4] developed Heart Attack Prediction Using Deep Learning in which This paper proposes a heart attack prediction system using Deep learning procedures, explicitly Recurrent Neural System to predict the probable prospects of heart related infections of the patient. Recurrent Neural Network is a very ground-breaking characterization calculation that utilizes Deep Learning approach in Artificial Neural Network. The paper talks about in detail the significant modules of the framework alongside the related hypothesis. The proposed model deep learning and data mining to give the precise outcomes least blunders. This paper gives a bearing and point of reference for the advancement of another type of heart attack prediction platform. Prediction stage.

Lakshmana Rao et al,[5] Machine Learning Techniques for Heart Disease Prediction in which the contributing elements for heart disease are more (circulatory strain, diabetes, current smoker, high cholesterol, etc..). So, it is difficult to distinguish heart disease. Different systems in data mining and neural systems have been utilized to discover the seriousness of heart disease among people. The idea of CHD ailment is bewildering, in addition, in this manner, the disease must be dealt with warily. Not doing early identification, may impact the heart or cause sudden passing. The perspective of therapeutic science furthermore, data burrowing is used for finding various sorts of metabolic machine learning a procedure that causes the framework to gain from past information tests, models without being expressly customized. Machine learning makes rationale dependent on chronicled information.

Mr. Santhana Krishnan.J and Dr. Geetha.S, [6] Prediction of heart disease using machine learning algorithm This Paper predicts heart disease for Male Patient using Classification Techniques. The detailed information about Coronary Heart diseases such as its Facts, Common Types, and Risk Factors has been explained in this paper. The Data Mining tool used is WEKA (Waikato Environment for Knowledge Analysis), a good Data Mining Tool for Bioinformatics Fields. The all three available Interface in WEKA is used here; Naive Bayes, Artificial Neural Networks and Decision Tree are Main Data Mining Techniques and through this techniques heart disease is predicted in this System. The main Methodology used for prediction is Decision Trees like CART, C4.5, CHAID, J48, ID3 Algorithms, and Naive Bayes Techniques.
Avinash Golande et al,[7] proposed Heart Disease Prediction Using Effective Machine Learning Techniques in which Specialists utilize a few data mining strategies that are available to support the authorities or doctors distinguish the heart disease. Usually utilized methodology utilized are decision tree, k- closest and Naïve Bayes. Other unique characterization-based strategies utilized are packing calculation, Part thickness, consecutive negligible streamlining and neural systems, straight Kernel selfarranging guide and SVM (Bolster Vector Machine). The following area obviously gives subtleties of systems that were utilized in the examination.

V.V. Ramalingam et Al,[8] proposed Heart disease prediction using machine learning techniques in which Machine Learning algorithms and techniques have been applied to various medical datasets to automate the analysis of large and complex data. Many researchers, in recent times, have been using several machine learning techniques to help the health care industry and the professionals in the diagnosis of heart related diseases. This paper presents a survey of various models based on such algorithms and techniques and analyse their performance. Models based on supervised learning algorithms such as Support Vector Machines (SVM), KNearest Neighbour (KNN), Naïve Bayes, Decision Trees (DT), Random Forest (RF) and ensemble models are found very popular among the researchers and systems have been applied to different clinical datasets to robotize the investigation of huge and complex information. Numerous scientists, as of late, have been utilizing a few Machine Learning algorithms and techniques have been applied to various medical datasets to automate the analysis of large and complex data. Many researchers, in recent times, have been using several machine learning techniques to help the health care industry and the professionals in the diagnosis of heart related diseases. This paper presents a survey of various models based on such algorithms and techniques and analyze their performance. Models based on supervised learning algorithms such as Support Vector Machines (SVM), KNearest Neighbour (KNN), Naïve Bayes, Decision Trees (DT), Random Forest (RF) and ensemble models are found very popular among the researchers. strategies to enable the wellbeing to mind industry and the experts in the analysis of heart related sicknesses. This paper presents a review of different models dependent on such calculations and methods and analyze their exhibition. Models in light of directed learning calculations, for example, Support Vector Machines (SVM), K- Nearest Neighbour (KNN), Naïve Bayes, Decision Trees (DT), Random Forest (RF) and group models are discovered extremely well known among the scientists. 
TABLE I. A COMPARATIVE STUDY OF VARIOUS ALGORITHMS IN LITERATURE REVIEW

\begin{tabular}{|c|c|c|c|c|}
\hline YEAR & AUTHOR & PURPOSE & $\begin{array}{l}\text { TECHNIQUES } \\
\text { USED }\end{array}$ & ACCURACY \\
\hline 2016 & $\begin{array}{c}\text { Sonam } \\
\text { Nikhar[2] }\end{array}$ & $\begin{array}{l}\text { Prediction } \\
\text { of Heart } \\
\text { Disease } \\
\text { Using } \\
\text { Machine } \\
\text { Learning } \\
\text { Algorithms }\end{array}$ & $\begin{array}{l}\text { 1) Naïve Bayes } \\
\text { Classifier } \\
\text { 2)Decision tree }\end{array}$ & $\begin{array}{l}\text { Decision tree } \\
\text { has better } \\
\text { accuracy as } \\
\text { compared to } \\
\text { naîve Bayes } \\
\text { classifier. }\end{array}$ \\
\hline 2018 & $\begin{array}{c}\text { Aditi } \\
\text { Gavhane[3] }\end{array}$ & $\begin{array}{l}\text { Prediction } \\
\text { of Heart } \\
\text { Disease } \\
\text { Using } \\
\text { Machine } \\
\text { Learning }\end{array}$ & $\begin{array}{l}\text { 1) Multi-layer } \\
\text { perceptron } \\
\text { algorithm }\end{array}$ & $\begin{array}{l}\text { The MLP } \\
\text { gives best } \\
\text { Accuracy }\end{array}$ \\
\hline 2018 & $\begin{array}{c}\text { V.V. } \\
\text { Ramalingam[8] }\end{array}$ & $\begin{array}{l}\text { Heart } \\
\text { disease } \\
\text { prediction } \\
\text { using } \\
\text { machine } \\
\text { learning } \\
\text { techniques }\end{array}$ & $\begin{array}{l}\text { 1) Naïve Bayes } \\
\text { 2) Support } \\
\text { Vector Machine } \\
\text { 3) K - Nearest } \\
\text { Neighbour } \\
\text { 4) Decision } \\
\text { Tree } \\
\text { 5) Random } \\
\text { Forest } \\
\text { 6) Ensemble } \\
\text { Model }\end{array}$ & $\begin{array}{l}\text { SVM has } \\
\text { more } \\
\text { accuracy than } \\
\text { other } \\
\text { techniques. }\end{array}$ \\
\hline 2019 & $\begin{array}{c}\text { Abhay } \\
\text { Kishore1[4] }\end{array}$ & $\begin{array}{l}\text { Heart } \\
\text { Attack } \\
\text { Prediction } \\
\text { Using } \\
\text { Deep } \\
\text { Learning }\end{array}$ & 1) $\mathrm{RNN}$ & $\begin{array}{l}\text { RNN } \\
\text { accuracy } 92 \%\end{array}$ \\
\hline
\end{tabular}

\begin{tabular}{|c|c|c|c|c|}
\hline $\begin{array}{l}\text { YEA } \\
\text { R }\end{array}$ & AUTHOR & $\begin{array}{l}\text { PURPOS } \\
\text { E }\end{array}$ & $\begin{array}{l}\text { TECHNIQUE } \\
\mathrm{S} \\
\text { USED }\end{array}$ & $\begin{array}{l}\text { ACCURA } \\
\text { CY }\end{array}$ \\
\hline 2019 & $\begin{array}{l}\text { Mr. Santhana } \\
\text { Krishnan.J[6] }\end{array}$ & $\begin{array}{l}\text { Prediction } \\
\text { of Heart } \\
\text { Disease } \\
\text { Using } \\
\text { Machine } \\
\text { Learning } \\
\text { Algorithm } \\
\text { s. }\end{array}$ & $\begin{array}{l}\text { 1)Naïve Bayes } \\
\text { 2)Decision } \\
\text { Tree }\end{array}$ & $\begin{array}{c}\text { Decision } \\
\text { Tree }(\mathbf{9 1 \%} \\
\text { Accuracy })\end{array}$ \\
\hline 2019 & $\begin{array}{c}\text { Avinash } \\
\text { Golande[7] }\end{array}$ & $\begin{array}{l}\text { Heart } \\
\text { Disease } \\
\text { Prediction } \\
\text { Using } \\
\text { Effective } \\
\text { Machine } \\
\text { Learning } \\
\text { Technique } \\
\text { s }\end{array}$ & $\begin{array}{l}\text { 1)Decision } \\
\text { Tree } \\
\text { 2)KNN, } \\
\text { 3)K-mean } \\
\text { clustering } \\
\text { 4)Adaboost }\end{array}$ & $\begin{array}{c}\text { Decision } \\
\text { tree } \\
(\mathbf{8 6 . 6 0 \%} \\
\text { Accuracy) }\end{array}$ \\
\hline 2019 & $\begin{array}{c}\text { Senthilkumar } \\
\text { Mohan [1] }\end{array}$ & $\begin{array}{l}\text { Effective } \\
\text { Heart } \\
\text { Disease } \\
\text { Prediction } \\
\text { Using } \\
\text { Hybrid } \\
\text { Machine } \\
\text { Learning }\end{array}$ & $\begin{array}{l}\text { 1) Decision } \\
\text { tree } \\
\text { 2)Language } \\
\text { Model } \\
\text { 3)Support } \\
\text { Vector }\end{array}$ & $\begin{array}{l}\text { HRFLM } \\
(\mathbf{8 8 . 4 \%} \\
\text { Accuracy) }\end{array}$ \\
\hline
\end{tabular}

\begin{tabular}{|c|c|c|c|c|}
\hline & & $\begin{array}{l}\text { Technique } \\
\mathrm{s}\end{array}$ & $\begin{array}{l}\text { Machine } \\
\text { 4)Random } \\
\text { Forest } \\
\text { 5)Naïve Bayes } \\
\text { 6)Neural } \\
\text { Networks } \\
\text { 7)KNN } \\
\text { 8)HRFLM }\end{array}$ & \\
\hline 2019 & $\begin{array}{c}\text { A. } \\
\text { Lakshmanarao[5] }\end{array}$ & $\begin{array}{l}\text { Machine } \\
\text { Learning } \\
\text { Technique } \\
\text { s For Heart } \\
\text { Disease } \\
\text { Prediction }\end{array}$ & $\begin{array}{l}\text { 1)Random } \\
\text { Over sampling } \\
\text { 2)Synthetic } \\
\text { Minority } \\
\text { Oversampling } \\
\text { 3)Adaptive } \\
\text { synthetic } \\
\text { sampling } \\
\text { approach }\end{array}$ & $\begin{array}{c}\text { For random } \\
\text { oversampli } \\
\text { ng, SVM } \\
\text { given the } \\
\text { best } \\
\text { accuracy of } \\
\mathbf{8 2 . 3 0 \% . ~} \\
\text { For } \\
\text { Synthetic } \\
\text { Minority } \\
\text { Oversampli } \\
\text { ng, Random } \\
\text { Forest } \\
\text { given the } \\
\text { best } \\
\text { accuracy of } \\
\text { 91.3\% } \\
\text { For } \\
\text { Adaptive } \\
\text { synthetic } \\
\text { sampling, } \\
\text { Random } \\
\text { Forest } \\
\text { (90.3\% } \\
\text { Accuracy) }\end{array}$ \\
\hline
\end{tabular}

\section{CONCLUSION AND FUTURE WORK}

We have summarized different types of machine learning algorithms for prediction of heart disease. We elaborated various machine learning algorithms and worked towards finding the best algorithm by analysing their features. Every algorithm has given different result in different situations. Further it is analysed only marginal accuracy is achieved for predictive model of heart disease and hence more complex models are needed to increase the accuracy of predicting the early heart disease. In future we will propose methodology for early prediction of heart disease with high accuracy and minimum cost and complexity.

\section{ACKNOWLEDGMENT}

We express our sincere thanks to our Seminar Guide Prof. Madhura Kalbhor for her encouragement and support throughout our seminar, especially for the useful suggestions given during the course of seminar and having laid down the foundation for the success of this work. We would also like to thank our Research \& Innovation coordinator Prof. Dr. Swati Shinde and Seminar Coordinator Prof. Pallavi Dhade for their assistance, genuine support and guidance from early stages of the seminar. We would like to thank Prof. Dr. K. Rajeshwari, Head of Computer Engineering Department for her unwavering support during the entire course of this seminar work. We also thank all the teaching and nonteaching staff members for their help in making our seminar 
work successful. We also thank all the web communities for enriching us with their immense knowledge.

\section{REFERENCES}

[1] Senthilkumar Mohan, Chandrasegar Thirumalai, Gautam Srivastava —Effective Heart Disease Prediction Using Hybrid Machine Learning Techniques\|, Digital Object Identifier 10.1109/ACCESS.2019.2923707, IEEE Access, VOLUME 7, 2019 S.P. Bingulac, -On the Compatibility of Adaptive Controllers, „I Proc. Fourth Ann. Allerton Conf. Circuits and Systems Theory, pp. 8-16, 1994. (Conference proceedings)

[2] Sonam Nikhar, A.M. Karandikar" Prediction of Heart Disease Using Machine Learning Algorithms" International Journal of Advanced Engineering, Management and Science (IJAEMS) Infogain Publication,[Vol-2, Issue-6, June- 2016].I.S. Jacobs and C.P. Bean, "Fine particles, thin films and exchange anisotropy," in Magnetism, vol. III, G.T. Rado and H. Suhl, Eds. New York: Academic, 1963, pp. 271-350.

[3] Aditi Gavhane, Gouthami Kokkula, Isha Pandya, Prof. Kailas Devadkar (PhD)," Prediction of Heart Disease Using Machine Learning", Proceedings of the 2nd International conference on Electronics, Communication and Aerospace Technology (ICECA 2018).IEEE Conference Record \# 42487; IEEE Xplore ISBN:978-15386-0965-1

[4] Abhay Kishore1, Ajay Kumar2, Karan Singh3, Maninder Punia4, Yogita Hambir5," Heart Attack Prediction Using Deep Learning”, International Research Journal of Engineering and Technology (IRJET), Volume: 05 Issue: 04 | Apr-2018.

[5] A.Lakshmanarao, Y.Swathi, P.Sri Sai Sundareswar," Machine Learning Techniques For Heart Disease Prediction", International Journal Of Scientific \& Technology Research Volume 8, Issue 11, November 2019.

[6] Mr.Santhana Krishnan.J, Dr.Geetha.S," Prediction of Heart Disease Using Machine Learning Algorithms",2019 $1^{\text {st }}$ International Conference on Innovations in Information and Communication Technology(ICIICT), doi:10.1109/ICIICT1.2019.8741465.

[7] Avinash Golande, Pavan Kumar T," Heart Disease Prediction Using Effective Machine Learning Techniques", International Journal of Recent Technology and Engineering (IJRTE) ISSN: 2277-3878, Volume-8, Issue-1S4, June 2019.

[8] V.V. Ramalingam, Ayantan Dandapath, M Karthik Raja," Heart disease prediction using machine learning techniques: a survey", International Journal of Engineering \& Technology, 7 (2.8) (2018) 684-687.
[9] V. Manikantan and S. Latha, "Predicting the analysis of heart disease symptoms using medicinal data mining methods", International Journal of Advanced Computer Theory and Engineering, vol. 2, pp.46-51, 2013.

[10] M. S. Amin, Y. K. Chiam, K. D. Varathan, "Identification of significant features and data mining techniques in predicting heart disease," Telematics Inform., vol. 36, pp. 82-93, Mar.2019.

[11] S. M. S. Shah, S. Batool, I. Khan, M. U. Ashraf, S. H. Abbas, and S. A. Hussain, "Feature extraction through parallel probabilistic principal component analysis for heart disease diagnosis," Phys. A, Stat. Mech. Appl.,vol. 482, pp. 796-807,2017. doi:10.1016/j.physa.2017.04.113.

[12] Stephen F. Weng, Jenna Reps, Joe Kai1, Jonathan M. Garibaldi, Nadeem Qureshi,-Can machine-learning improvecardiovascular risk prediction using routine clinical data?\|, PLOS ONE | https://doi.org/10.1371/journal.pone. 0174944 April 4, 2017.

[13] N. Al-milli, _Backpropagation neural network for prediction of heart disease, "J. Theor. Appl.Inf. Technol., vol. 56, no. 1, pp.131-135, 2013.

[14] A. S. Abdullah and R. R. Rajalaxmi, "A data mining model for predicting the coronary heart disease using random forest classifier,' in Proc. Int. Conf. Recent Trends Comput. Methods, Commun. Controls, Apr. 2012, pp. 22-25. 